\title{
ABSOLUTE CONVERGENCE OF SERIES OF FOURIER COEFFICIENTS
}

BY

JAMES R. MCLAUGHLIN

ABSTRACT. In this article the author unifies and generalizes practically all known sufficiency results for absolute convergence of series of Fourier coefficients that are given in terms of the integrated modulus of continuity, best approximation, or bounded pth variation. This is done for the trigonometric, Walsh, Haar, Franklin, and related systems as well as general orthonormal systems. Many of the original proofs of previous results relied upon special properties of the trigonometric, Haar, and other systems and were done independently of one another. Also, several authors have proved results which at the time they believed to be generalizations of past results, but are, in fact, corollaries of them. The present author will expose underlying principles and illustrate their usefulness.

1. Introduction. In this paper we are concerned with sufficiency conditions on functions / which imply

$$
\sum_{k=1}^{\infty}\left|a_{k}\right|^{\beta}{ }^{\gamma}<\infty
$$

or

$$
\sum_{k=1}^{\infty}\left|a_{k}\right|^{\beta}<\infty \text { and } \sum_{k=1}^{\infty}\left|a_{k}\right| k^{\gamma}<\infty
$$

where $\left\{a_{k}\right\}$ denotes the Fourier coefficients of the function $f$ with respect to some orthonormal system in question. Most results in this area are generalizations of classical theorems of S. Bernšteĭn, A. Zygmund, O. Szász, and S. Stechkin. We will find that many of these follow simply from Bessel's inequality and

$$
E_{2}(f, k)=O\left[\omega_{2}\left(f, k^{-1}\right)\right] \text {. }
$$

In $\$ 2$ we give definitions and notations that will be used throughout the article.

In $\$ 3$ twenty previous theorems are stated. Among the results listed there which we shall unify are results of I. I. Hirschman, M. and S. Izumi, S. L. Bljumin

Received by the editors December 20, 1972.

AMS (MOS) subject classifications (1970). Primary 42A16, 42A28, 42A56, 42A60; Secondary $41 \mathrm{~A} 50$.

Key words and phrases. Integrated modulus of continuity, best approximation, bounded pth variation, Lipschitz conditions, quasi-monotone sequences, trigonometric system, Walsh system, generalized Walsh system, Haar system, Franklin system, generalized Haar system, general orthogonal series, basis in $L^{p}$. 
and B. D. Kotljar, C. Onneweer, as well as the author concerning (1.1) with respect to the trigonometric, Walsh, and generalized Walsh system-especially Fourier coefficients of functions of bounded $p$ th variation. We also list a result of S. B. Stechkin concerning absolute convergence of general Fourier series. Other results listed which will also be generalized are results of $Z$. Ciesielski and J. Musielak, P. L. Ul'yanov, B. I. Golubov, B. I. Golubov and A. I. Rubinštein, Z. Ciesielski, and T. S. Tevzadze for the Haar, Franklin, and generalized Haar system.

In $\S 4$ there are given numerous previous lemmas which will be used in the sequel.

In $\$ 5$ we add several new lemmas.

In $\$ 6$ we prove the analogue of A. Konyushkov's 1958 sufficiency result, involving (1.1) with respect to the trigonometric system, for the Walsh and generalized Walsh system. We also give new results.

In $\$ 7$ we prove that the ana logue of Konyushkov's 1958 result is also true for any uniformly bounded orthonormal sequence which forms a basis in $L^{p}(a, b)$ for $1 \leq p \leq 2$.

In $\$ 8$ we take the opportunity to enlarge Stechkin's 1951 result in scope while simplifying its proof. With this we are able to show that the majority of the previous theorems listed in $\$ 4$ are easy consequences of Bessel's inequality and (1.3). We also give new results.

In $\$ 9$ we prove that the analogue of Ciesielski and Musielak's 1959 result, involving (1.1) with respect to the Haar system, is also valid for the Franklin and generalized Haar system. Other new results are also obtained.

In $\oint 10$ the author makes some concluding remarks.

2. Definitions and notation.

Definition 2.1. The modulus of continuity of $f$ on $[a, b]$ for $f$ periodic of period $b-a$ is

$$
\omega(f, \delta)=\sup _{0<b \leq \delta}|f(x+b)-f(x)| .
$$

Definition 2.2. The integrated modulus of continuity of $f \in L^{p}[a, b]$ for $f$ of period $b-a$ and $0<p \leq \infty$ is

$$
\omega_{p}(f, \delta)=\sup _{0<b \leq \delta}\left\{(b-a)^{-1} \int_{a}^{b}|f(x+b)-f(x)|^{p} d x\right\}^{1 / p}
$$

where we set $\omega_{\infty}(f, \delta)=\omega(f, \delta)$.

Definition 2.3. $f \in \operatorname{Lip} a, a>0$, if $\omega(f, b)=O\left(b^{a}\right)$.

Definition 2.4. $f \in \operatorname{Lip}(a, p), 0<a \leq 1, p>0$, if $\omega_{p}(f, b)=O\left(b^{\alpha}\right)$. 
Definition 2.5. $f$ is of bounded pth variation on $[a, b]$ for $0<p<\infty$, abbreviated $f \in \operatorname{Var} p$, if

$$
V_{p}=\sup \left\{\sum_{i=1}^{n}\left|f\left(x_{i}\right)-f\left(x_{i-1}\right)\right|^{p}\right\}^{1 / p}<\infty
$$

where the supremum is taken over all partitions $a=x_{0}<x_{1}<\cdots<x_{n}=b$ of $[a, b]$.

Definition 2.6. $A_{p}(f)=\left\{(b-a)^{-1} \int_{a}^{b}|f(x)|^{p} d x\right\}^{1 / p}, p>0$.

Definition 2.7. If $f$ is an absolutely continuous function, set

$$
V(f, k)=\int_{E_{k}}\left|f^{\prime}(x)\right| d x
$$

where $E_{k}=\left\{x: 0 \leq x \leq 1\right.$ and $\left.\left|f^{\prime}(x)\right|>k\right\}$.

Definition 2.8. For a real or complex sequence $b=\left\{b_{k}\right\}$, we set

$$
\|b\|_{p}=\left(\sum_{k=1}^{\infty}\left|b_{k}\right|^{p}\right)^{1 / p} \text { for } 0<p<\infty \text { and }\|b\|_{\infty}=\sup _{1 \leq k<\infty}\left|b_{k}\right| .
$$

Definition 2.9. A sequence $\left\{c_{k}\right\}$ of positive numbers is quasi-monotone if $c_{k} / k^{\beta} \downarrow 0$ for some real $\beta$.

Definition 2.10. Assume $\left\{n_{k}\right\}$ is a sequence of integers, $n_{k} \geq 2$, and $p_{k}=$ $n_{1} n_{2} \cdots n_{k}$ for $k \geq 1$. Assume also that $0 \leq b<1,0 \leq x<1$, and that

$$
x=\sum_{k=1}^{\infty} x_{k} / p_{k}, \quad 0 \leq x_{k}<n_{k}, \quad \text { and } \quad b=\sum_{k=1}^{\infty} h_{k} / p_{k}, \quad 0 \leq b_{k}<n_{k},
$$

where the terminating expansion is taken in case $x$ or $b$ are of the form $m / p_{k}$. Then we define (cf. $[6$, p. 18], [22, p. 414], [29, p. 238]) the binary operation* on $[0,1) \times[0,1)$ by

$$
x * b=\sum_{k=1}^{\infty} c_{k} / p_{k} \text { where } c_{k}=\left(x_{k}+b_{k}\right) \bmod n_{k}, \quad 0 \leq c_{k}<n_{k} .
$$

Definition 2.11. If $f \in L^{p}[a, b]$ for $f$ of period $b-a$ and $1 \leq p \leq \infty$, then we define (assuming integrability of $f(x * b)$ )

$$
\Omega_{p}(f, \delta)=\sup _{0<b \leq \delta}\left\{(b-a)^{-1} \int_{a}^{b}|f(x * b)-f(x)|^{p} d x\right\}^{1 / p}, \quad 1 \leq p<\infty,
$$

and

$$
\Omega_{\infty}(f, \delta)=\sup _{0<b \leq \delta}|f(x * b)-f(x)| .
$$

Definition 2.12. The trigonometric, Walsh, and generalized Walsh system (as defined in [22]) originating from N. Ya. Vilenkin [28] will be denoted by $T$, $W$, and $W\left\{n_{i}\right\}$ where the $n_{i}$ are arbitrary integers $n_{i} \geq 2$ as in $[22, \mathrm{p} .413]$ but in 
this article will be assumed bounded unless otherwise specified. Also, for simplicity, we index the Walsh functions from 1 to $\infty$ rather than from 0 to $\infty$ as is usually done.

Definition 2.13. The Haar, Franklin, and generalized Haar system (as defined in [13]) will be denoted by $H, F$, and $H\left\{n_{i}\right\}$ where the $n_{i}$ are arbitrary integers $n_{i} \geq 2$ as in [13, p. 225] but will be assumed bounded unless otherwise noted. For simplicity, we index the Haar functions from 1 to $\infty$.

Definition 2.14. An orthonormal system (or an ON system) $\left\{\varphi_{k}\right\}$ is a strong ON system (or a SON system) in $L^{p}(\mu), 1 \leq p \leq \infty$ (where $(X, A, \mu)$ is a measure space and $L^{\infty}=C$ here) if $\lim _{n \rightarrow \infty}\left\|f-S_{n}(f)\right\|_{p}=0$ for every $f \in L^{p}$ where throughout this paper $S_{n}(f, x)$ will denote the $n$th partial sum of the Fourier series of $f$ evaluated at $x$. If $\left\{\varphi_{k}\right\} \subset L^{p}$, SON in $L^{p}$ means $\left\{\varphi_{k}\right\}$ is a basis for the space $L^{p}(\mu)$.

Definition 2.15. An ON system is a complete ON system (or a CON system) if it is a SON system for $p=2$. If an ON system is a uniformly bounded system, we say it is a BON system. If a BON system is a strong ON system, we say it is a SBON system.

Definition 216. $f \in A$ for an ON system $\left\{\varphi_{k}\right\}$, if the series of Fourier coefficients of $f$ with respect to $\left\{\varphi_{k}\right\}$ is absolutely convergent.

Definition 2.17. The best approximation of order $n$ to $f \in L^{p}[a, b]$ for an ON system in $L^{p}$ is

$$
E_{p}(f, n)=\inf \left\{\int_{a}^{b}\left|f(x)-T_{n}(x)\right|^{p} d x\right\}^{1 / p}
$$

where the infimum is taken over all ON polynomials of degree not higher than $n, n=1,2, \cdots$.

Definition 2.18. Unless otherwise specified we shall reserve the notation $\left\{a_{k}\right\}$ to denote the Fourier coefficients with respect to the system (or systems) and function in question. We will also use the abbreviation

$$
S_{p}(n, m)=\left(\sum_{k=n+1}^{m}\left|a_{k}\right|^{p}\right)^{1 / p} \text { for } m>n \text {. }
$$

Definition 2.19. For any sequence of bounded real or complex integrable functions $\left\{\boldsymbol{\varphi}_{k}\right\}$ we define, for $1 / p+1 / q=1$, the abbreviation for $m>n$ :

$$
\Phi_{p}(n, m)=\left\|\sum_{k=n+1}^{m}\left|\varphi_{k}(x)\right|\right\|_{\infty}^{1 / p}\left(\max _{n<k \leq m}\left\|\varphi_{k}\right\|_{1}\right)^{1 / q} .
$$

3. Some previous theorems.

Theorem 3.1 (O. Szász [2, II, p. 197], G. Hardy and H. Wehl [34, I, p. 251]: 
B. Golubov and A. Rubinštein [14, p. 107]). If $f \in$ Lip $a, 0<a \leq 1$, then (1.2) is satisfied for

$$
\beta>2 /(2 a+1) \text { and } \gamma<a-1 / 2
$$

for $T$ and $H\left\{n_{i}\right\}$ where $\left\{n_{i}\right\}$ are prime integers also.

Theorem 3.2 (S. Bockarev [4, p. 58]). For every $\operatorname{CON}$ system on $[0,1]$, there exists an $f \in \operatorname{Lip} \alpha, 0<\alpha<1$, such that

$$
\sum_{k=1}^{\infty}\left|a_{k}\right|^{\beta}=\infty \text { and } \sum_{k=1}^{\infty}\left|a_{k}\right| k^{\gamma}=\infty
$$

for $\beta=2 /(2 \alpha+1)$ and $\gamma=\alpha-1 / 2, \gamma>0$.

Theorem 3.3 (Szász [34, I, p. 241]: S. Bljumin and B. Kotljar [3, Corollary 4]). If $f \in \operatorname{Var} 1$ and $f \in \operatorname{Lip} a$ for some $a>0$, then $f \in A$ for $T$ and $W$.

Theorem 3.4 (Bozkarev announced in [5, p. 226]). For every CBON system on $[0,1]$, there exists an absolutely continuous function $f$ sucb that $f \notin A$.

Theorem 3.5 (Szász [34, I, p. 243]). If $f \in \operatorname{Var} 1$ and $f \in \operatorname{Lip} a, 0<a \leq 1$, then, with respect to the $T$ system, $\Sigma_{k=1}^{\infty}\left|a_{k}\right|^{\beta}<\infty$ for $\beta>2 /(2+\alpha)$.

Theorem 3.6 (Bočkarev [4, p. 65], [5, p. 227]). For every CBON system on $[0,1], 0<\alpha \leq 1$, there exist an $f \in \operatorname{Var} 1$ and $f \in \operatorname{Lip}$ a such that $\Sigma_{k=1}^{\infty}\left|a_{k}\right|^{\beta}=\infty$ for all $\beta \leq 2 /(2+\alpha)$.

Theorem 3.7 (A. Zygmund [34, I, p. 242]). If $f \in \operatorname{Var} 1$ and $\sum_{k=1}^{\infty} k^{-1}\left[\omega\left(f, k^{-1}\right)\right]^{1 / 2}$ $<\infty$, then $f \in A$ for $T$.

Theorem 3.8 (I. Hirschman [15, Lemma 2d]). If $f \in \operatorname{Var} p, 1 \leq p<2$, and $f \epsilon$ Lip a for $a>0$, then $f \in A$ for $T$.

Theorem 3.9 (M. and S. Izumi [16]: T. Tevzadze announced in [26]). If $1<$ $p<\infty, 1 / p+1 / q=1,1 \leq r<2 p, f \in \operatorname{Var} r$, and satis/ies

then $f \in A$ for $T$ and $H$.

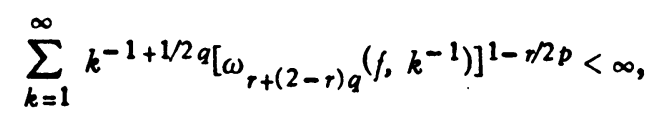

Theorem 3.10 (Szász [34, I, p. 251]: Bljumin and Kotljar [3, Corollary 3]). If $f \in \operatorname{Lip}(\alpha, p)$ for $0<\alpha \leq 1$ and $1 \leq p \leq 2$, then $\Sigma_{k=1}^{\infty}\left|a_{k}\right|^{\beta}<\infty$ for $\beta>$ $p /[p(1+\alpha)-1]$ for $T$ and $W$.

Theorem 3.11 (I. Wik [32, Theorem 7.4]). If $/$ is absolutely continuous, then $f \in A$ for $T$ whenever 


$$
\sum_{k=1}^{\infty} k^{-1}\left[\omega\left(f, k^{-1}\right) \cdot V(f, k)\right]^{1 / 2}<\infty,
$$

where we are using Definition 2.7 bere.

Theorem 3.12 (Szász [2, II, p. 155]: J. McLaughlin [19, Theorem 7]). If $f$ satisfies $\Sigma_{k=1}^{\infty} k^{-1 / 2} \omega_{2}\left(f, k^{-1}\right)<\infty$, then $f \in A$ for $T$ and $W$.

Theorem 3.13 (Golubov [12, Theorem 6]). If $f \in \operatorname{Var} p, 2 \leq p<\infty$, then, with respect to the $T$ system, $\Sigma_{k=1}^{\infty}\left|a_{k}\right|^{\beta}<\infty$ for $\beta>2 p /(2+p)$.

Theorem 3.14 (A. Konyushkov [17, p. 74]). If $1<p \leq 2$ and $0<\beta \leq q, \gamma \geq$ $-1,1 / p+1 / q=1$, and

$$
\sum_{k=1}^{\infty} k^{\gamma-\beta / q}\left[E_{p}(f, k)\right]^{\beta}<\infty
$$

then (1.1) is satisfied for $T$.

Theorem 3.15 (S. Stechkin [24, Theorem 3]). If $f \in L^{2}[a, b]$ and $\{m(k)\}$ is an increasing sequence of positive integers, then for any ON system on $[a, b]$

$$
\sum_{k=1}^{\infty}\left|a_{m(k)}\right| \leq(2 / \sqrt{ } 3) \sum_{k=1}^{\infty} k^{-1 / 2} E_{2}(f, m(k)-1) \text {. }
$$

Theorem 3.16 (Z. Ciesielski and J. Musielak [9, Theorem 2]). If $\beta>0, \gamma \geq$ 0 and $f$ satisfies

$$
\sum_{k=1}^{\infty} k^{\gamma-\beta / 2}\left[\omega_{\mu}\left(f, k^{-1}\right)\right]^{\beta}<\infty, \quad \mu=\max (\beta, 1),
$$

then (1.1) is satisfied for $H$.

Theorem 3.17 (Ciesielski and Musielak [9, Theorem 3]). If $f \in \operatorname{Var} p, 1 \leq p<$ 2 , and

$$
\sum_{k=1}^{\infty} k^{-1}\left[\omega\left(f, k^{-1}\right)\right]^{1-p / 2}<\infty
$$

then $f \in A$ for $H$.

Theorem 3.18 (P. Ul'yanov [27, p. 373]: Ciesielski [8, Theorem 17]). If $f \epsilon$ Var 1 , then (1.2) is satisfied for $\beta>2 / 3$ and $\gamma<1 / 2$ for $H$ and $F$.

Theorem 3.19 (Golubov [11, p. 1291]: Golubov and Rubinštein [14, p 109]). If $f \in \operatorname{Var} p, p \geq 1$, then (1.2) is satisfied for

$$
\beta>2 p /(2+p) \text { and } \gamma<1 / p-1 / 2
$$

for $H$ and $H\left\{n_{i}\right\}$ if $\left\{n_{i}\right\}$ is also a sequence of prime integers. 
Theorem 3.20 (Ciesielski [8, p. 318]). If $f$ satisfies $\sum_{k=1}^{\infty} k^{-1 / 2} \omega_{1}\left(f, k^{-1}\right)<$ $\infty$, then $f \in A$ for the $F$ system.

Remark 3.1. The interested reader should be able to trace down all the authors whose work culminated in Theorems 3.1-3.20 through the references in this paper. Also, some recent results appearing in [20] concerning $W\left\{n_{i}\right\}$ will be noted later in this paper.

4. Previous lemmas.

Lemma 4.1 [34, I, p. 25]. $A_{p}(f)$ is a nondecreasing function of $p$ for $p>0$, and bence so is $\omega_{p}(f, \delta)$.

Lemma 4.2 [33, p. 258]. $V_{p}(f)$ is a nonincreasing function of $p$ for $p>0$.

Lemma 4.3 [33, p. 259]. If $f \in \operatorname{Lip} \alpha$, then $f \in \operatorname{Var} \alpha^{-1}$ on $[a, b]$ for $\alpha>0$.

Lemma 4. 4 [33, p. 259]. If $f \in \operatorname{Var} p$, then $f \in \operatorname{Lip}\left(p^{-1}, p\right)$ for $p>0$.

Lemma 4.5 (Szász [25]). If $\left\{m_{n}\right\}$ is a strictly increasing sequence of positive integers such that

$$
m_{n+1}-m_{n}=O\left(m_{n}-m_{n-1}\right)
$$

and $\left\{b_{m}\right\}$ is a quasi-monotone sequence of positive numbers, then the two series

$$
\sum_{n=1}^{\infty} b_{n} \text { and } \sum_{n=1}^{\infty}\left(m_{n}-m_{n-1}\right) b_{m_{n}}
$$

are either both convergent or both divergent.

Lemma 4.6 (M. Riesz [2, II, p. 138]: R. Paley [21, p. 255]). The systems $T$ and $W$ are SON systems for $1<p<\infty$.

Lemma 4.7 (Ul'yanov [27, p. 384]: Ciesielski [7, p. 145]: Golubov and Rubinštein [14, p. 104] and Golubov [13, pp. 233, 237]). The systems $H, F$ and $H\left\{n_{i}\right\}$ are SON systems for $1 \leq p \leq \infty$.

Lemma 4.8 (Golubov [13, Theorem 4]). For arbitrary positive integers $n_{i} \geq 2$, $H\left\{n_{i}\right\}$ is a SON system if $1<p<\infty$.

Lemma 4.9. If $\left\{\varphi_{k}\right\}$ is an ON system (real or complex on $L^{2}(\mu)$ where $(X, A$, $\mu)$ is a measure space) and $\left\{b_{k}\right\}$ and $\left\{c_{k}\right\}$ are any real or complex sequences, then by Hölder's inequality if $1 / p+1 / q=1$ and $p \geq 1$

$$
\left|\sum_{k=m}^{n} b_{k} c_{k}\right| \leq\left\|\sum_{k=m}^{n} b_{k} \varphi_{k}\right\|_{p} \cdot\left\|\sum_{k=m}^{n} c_{k} \varphi_{k}\right\|_{q} .
$$

Lemma 4.10. For any $O N\left\{\varphi_{k}\right\}$, if $p \geq 1$, then 


$$
\left\|\sum_{k=m+1}^{n} a_{n} \varphi_{k}\right\|_{p} \leq\left\|f-S_{m}(f)\right\|_{p}+\left\|f-S_{n}(f)\right\|_{p}, \quad n>m .
$$

Proof. $\left\|\Sigma_{k=m+1}^{n} a_{k} \varphi_{k}\right\|_{p}=\left\|S_{n}(f)-S_{m}(f)+f-f\right\|_{p}$.

Lemma 4.11. If $\left\{\varphi_{k}\right\}$ is a SON system for some $p, 1 \leq p \leq \infty$, then by the Banach-Steinbaus Theorem [34, I, p. 165] we have for some constant $K$

$$
\left\|S_{n}(f)\right\|_{p} \leq K\left\|_{f}\right\|_{p} \text { for every } f \in L^{p} \text {. }
$$

Lemma 4.12. If an ON system $\left\{\varphi_{k}\right\}$ satisfies (4.3) for some $p, 1 \leq p \leq \infty$, and a constant $K$, then $E_{p}(f, n) \leq\left\|f-S_{n}(f)\right\|_{p} \leq(1+K) E_{p}(f, n)$.

Proof.

$$
\begin{aligned}
E_{p}(f, n) & \leq\left\|f-S_{n}(f)\right\|_{p} \leq\left\|f-T_{n}\right\|_{p}+\left\|S_{n}(f)-T_{n}\right\|_{p} \\
& \leq\left\|f-T_{n}\right\|_{p}+\left\|S_{n}\left(f-T_{n}\right)\right\|_{p} \leq(1+K)\left\|_{f}-T_{n}\right\|_{p}
\end{aligned}
$$

where $T_{n}$ is any orthogonal polynomial of order not higher than $n$.

Lemma 4.13 (Stechkin [17, p. 81]: Ul'yanov [27, p. 384]: Ciesielski [8, p. 313]: Golubov and Rubinstein [14, p. 104] and Golubov [13, pp. 233, 236]). For T, $H, F$, and $H\left\{n_{i}\right\}$, if $1 \leq p \leq \infty$, then $E_{p}(f, n)=O\left[\omega_{p}\left(f, n^{-1}\right)\right]$.

Lemma 4.14 (C. Watari [30, p. 3]). For the system $w$, if $1 \leq p \leq \infty$, then (using Definition 2.11)

$$
E_{p}\left(f, 2^{n}\right) \leq \Omega_{p}\left(f, 2^{-n}\right) \leq 2 E_{p}\left(f, 2^{n}\right)
$$

Lemma 4.15 (McLaughlin [19, proof of Theorem 7]). For $W$, if $1 \leq p \leq \infty$, then $\Omega_{p}\left(\gamma, 2^{-n}\right) \leq 2 \omega_{p}\left(f, 2^{-n}\right)$, and so by Lemma 4.14 we also bave

$$
E_{p}(f, n)=O\left[\omega_{p}\left(f, n^{-1}\right)\right], \quad 1 \leq p \leq \infty .
$$

Lemma 4.16 (Ciesielski and Musielak [9, p. 63]). For $H$ (using Definition 2.18 and the indexing in [27])

$$
\begin{array}{ll}
S_{p}\left(2^{n}, 2^{n+1}\right)=O\left[\omega_{1}\left(f, 2^{-n}\right) \cdot 2^{n(1 / p-1 / 2)}\right], & 0<p \leq 1, \\
S_{p}\left(2^{n}, 2^{n+1}\right)=O\left[\omega_{p}\left(f, 2^{-n}\right) \cdot 2^{n(1 / p-1 / 2)}\right], & 1 \leq p \leq \infty .
\end{array}
$$

Lemma 4.17 (Golubov and Rubinštein [14, p. 98]). For the system $H\left\{p_{i}\right\}$, for $\left\{p_{i}\right\}$ also prime integers, and $m_{n}=p_{1} \cdot p_{2} \cdots p_{n}$ we have

$$
S_{p}\left(m_{n}, m_{n+1}\right)=O\left[\omega_{p}\left(f, 1 / m_{n}\right) \cdot m_{n}^{(1 / p-1 / 2)}\right], \quad 1 \leq p \leq \infty .
$$

Lemma 4.18 (F. Riesz: Hausdorff-Young [34, II, p. 102]). If $\left\{\varphi_{k}\right\}$ is BON in 
$L^{2}(\mu), 1 \leq p \leq 2$, and $f \in L^{p}(\mu)$, then for $1 / p+1 / q=1$ and the uniform bound $M$ we bave $\bar{S}_{q}(1, \infty) \leq M^{(2-p) / p}\|f\|_{p}$.

Lemma 4.19 (Ciesielski [8, pp. 307-308]). For $F$ we bave (using Definition 2.19) $\Phi_{p}\left(2^{n}, 2^{n+1}\right)=O\left[2^{n(1 / p-1 / 2)}\right], 1 \leq p \leq \infty$.

5. Lemmas.

Lemma 5.1. Let $1 \leq s<\infty, 1<p<\infty, 1 / p+1 / q=1$, and $1 \leq r<s p$. Then

$$
\omega_{s}(f, \delta) \leq\left[\omega_{r}(f, \delta)\right]^{r / s p}\left[\omega_{r+(s-r) q}(f, \delta)\right]^{1-r / s p} \text {. }
$$

Proof. $s=r / p+(s-r / p)=r / p+[r+(s-r) q] / q$. Hence, by Hölder's inequality,

$$
\begin{gathered}
\int_{a}^{b}|f(x+b)-f(x)|^{s} d x \\
\leq\left[\int_{a}^{b}|f(x+b)-f(x)|^{r} d x\right]^{1 / p}\left[\int_{a}^{b}|f(x+b)-f(x)|^{r+(s-r) q} d x\right]^{1 / q}, \\
(b-a)^{-1} \int_{a}^{b}|f(x+b)-f(x)|^{s} d x \\
\leq\left[(b-a)^{-1} \int_{a}^{b}|f(x+b)-f(x)|^{r} d x\right]^{1 / p} \\
\cdot\left[(b-a)^{-1} \int_{a}^{b}|f(x+b)-f(x)|^{r+(s-r) q} d x\right]^{1 / q} .
\end{gathered}
$$

Lemma 5.2. If $f \in \operatorname{Var} r, 1 \leq s<\infty, 1<p<\infty, 1 / p+1 / q=1$, and $1 \leq r<s p$, then by Lemmas 4.4 and 5.1

$$
\omega_{s}(f, \delta)=O\left\{\delta^{1 / s p}\left[\omega_{r+(s-r) q}(f, \delta)\right]^{1-r / s p}\right\} .
$$

Lemma 5.3. If $0<\beta<p$ and $f$ is bounded, then, by definition of $\omega_{p}(f, \delta)$,

$$
\omega_{p}(f, \delta) \leq[\omega(f, \delta)]^{1-\beta / p}\left[\omega_{\beta}(f, \delta)\right]^{\beta / p} \text {. }
$$

Lemma 5.4. For $H\left\{p_{i}\right\}$, for $\left\{p_{i}\right\}$ also prime integers, we bave (using the notation of Lemma 4.17)

$$
S_{p}\left(m_{n^{\prime}} m_{n+1}\right)=O\left[\omega_{1}\left(f, 1 / m_{n}\right) \cdot m_{n}^{(1 / p-1 / 2)}\right], . \quad 0<p \leq 1 .
$$

Proof. By Lemma 4.17 we have 
300

J. R. McLAUGHLIN

$$
\begin{aligned}
\sum_{k=m_{n}+1}^{m_{n+1}}\left|a_{k}\right|^{p} & \leq\left(\sum_{k=m_{n}+1}^{m_{n+1}}\left|a_{k}\right|^{p / p}\right)^{p}\left(m_{n+1}-m_{n}\right)^{1-p} \\
& =O\left[\omega_{1}\left(f, 1 / m_{n}\right) m_{n}^{1 / 2}\right]^{p}\left(m_{n+1}-m_{n}\right)^{1-p} \\
& =O\left\{\left[\omega_{1}\left(f, 1 / m_{n}\right)\right]^{p} m_{n}^{p / 2} m_{n}^{1-p}\left[\left(m_{n+1}-m_{n}\right) / m_{n}\right]^{1-p}\right\} \\
& =O\left\{\left[\omega_{1}\left(f, 1 / m_{n}\right)\right]^{p} m_{n}^{1-p / 2}\right\}, \text { since } m_{n+1} / m_{n}=O(1) .
\end{aligned}
$$

Lemma 5.5. For $H$ we have, if $1 \leq p \leq \infty, \Phi_{p}\left(2^{n}, 2^{n+1}\right)=O\left[2^{n(1 / p-1 / 2)}\right]$.

Proof. $\Phi_{p}\left(2^{n}, 2^{n+1}\right)=2^{n / 2 p} \cdot 2^{-n / 2 q}=2^{n(1 / p-1 / 2)}$.

Lemma 5.6. For $H\left\{p_{i}\right\}$, where $\left\{p_{i}\right\}$ may be unbounded integers, with $m_{i}=$ $p_{1} p_{2} \cdots p_{i}$, if $1 \leq p \leq \infty$

$$
\Phi_{p}\left(m_{n}, m_{n+1}\right)=\left(p_{n+1}-1\right)^{1 / p}\left(m_{n}\right)^{1 / p-1 / 2} .
$$

Proof. $\Phi_{p}\left(m_{n}, m_{n+1}\right)=\Phi_{p}\left(m_{n}, m_{n} \cdot p_{n+1}\right)=\left[m_{n}^{1 / 2}\left(p_{n+1}-1\right)\right]^{1 / p} m_{n}^{-1 / 2 q}$.

Lemma 5.7. For the system $H\left\{p_{i}\right\}$ in Lemma 5.6 with $\left\{p_{i}\right\}$ bounded, if $1 \leq$ $p \leq \infty$

$$
\Phi_{p}\left(m_{n}, m_{n+1}\right)=O\left[m_{n}^{(1 / p-1 / 2)}\right] .
$$

Lemma 5.8. If $\left\{c_{k}\right\}$ is any sequence of real or complex numbers, $\left\{\varphi_{k}\right\}$ is any sequence of real or complex bounded functions in the Banach space $L^{1}(\mu)$ for a measure space $(X, A, \mu), 1 \leq p \leq \infty$, then for $m>n$ and $1 / p+1 / q=1$

$$
\left\|\sum_{k=n+1}^{m} c_{k} \varphi_{k}\right\|_{q} \leq\left(\sum_{k=n+1}^{m}\left|c_{k}\right|^{q}\right)^{1 / q} \Phi_{p}(n, m) .
$$

Proof.

$$
\begin{aligned}
\int_{X}\left[\sum\left|c_{k}\right|\left|\varphi_{k}\right|\right]^{q} d \mu=\int_{X}\left[\sum\left|c_{k}\right|\left|\varphi_{k}\right|^{1 / q}\left|\varphi_{k}\right|^{1 / p}\right]^{q} d \mu \\
\leq \int_{X}\left[\left(\sum\left|c_{k}\right|^{q}\left|\varphi_{k}\right|\right)^{1 / q}\left(\sum\left|\varphi_{k}\right|\right)^{1 / p}\right]^{q} d \mu \quad \text { by Hölder's inequality } \\
\quad=\int_{X}\left(\sum\left|c_{k}\right|^{q}\left|\varphi_{k}\right|\right)\left(\sum\left|\varphi_{k}\right|\right)^{q-1} d \mu \\
\leq\left\|\sum\left|\varphi_{k}\right|\right\|_{\infty}^{q-1} \int_{X}\left(\sum\left|c_{k}\right|^{q}\left|\varphi_{k}\right|\right) d \mu \\
\left.\leq\left\|\sum\left|\varphi_{k}\right|\right\|_{\infty}^{q-1} \max _{n<k \leq m} \int_{X}\left|\varphi_{k}\right| d \mu\right) \sum\left|c_{k}\right|^{q} .
\end{aligned}
$$


Remark 5.1. Lemma 5.8 was stated for $F$ by Ciesielski [8, p. 307, Inequality 31] and was used in the proofs of Theorems 3.18 and 3.20 for $F$. The present author is giving an independent proof of this result, since there appears to be an error in Ciesielski's proof (second line from the bottom of [8, p. 307]) since if $c=\left\{c_{k}\right\}$ is any nonnegative sequence, $\|c\|_{\alpha}$ is a nonincreasing function of $a$ for $a>0$, and so the last inequality of Ciesielski's is backwards. Many of the results given in this article about the system $F$ and $H\left\{n_{i}\right\}$ were motivated by this interesting correct assertion of Ciesielski as well as Ciesielski and Musielak's 1959 paper [9].

Lemma 5.9. For the binary operation $*$ given in Definition 2.10 we have that if $f \in L[0,1]$, then for every fixed $b, f(x * b) \in L[0,1]$ and $\int_{0}^{1} f(x) d x=$ $\int_{0}^{1} f(x * b) d x$.

Proof (cf. [6, p. 19], [10, p. 379]). The operation * is a measure preserving transformation of $[0,1)$ onto $[0,1)[22, p .414]$. In fact, if $b \in\left[j / p_{k},(j+1) / p_{k}\right)$ and $x \in\left[i / p_{k},(i+1) / p_{k}\right)$, then

$$
\begin{aligned}
x * b & =\left[M n_{k}+(i+j) \bmod n_{k}\right] / p_{k}+\sum_{i=k+1}^{\infty}\left[\left(x_{i}+b_{i}\right) \bmod n_{i}\right] / p_{i} \\
& =N / p_{k}+\sum_{i=k+1}^{\infty}\left[\left(x_{i}+b_{i}\right) \bmod n_{i}\right] / p_{i}
\end{aligned}
$$

where $M$ and $N$ are uniquely determined by $x$ (for $b$ fixed). Hence if $x$ has domain $\left[i / p_{k},(i+1) / p_{k}\right)$, the range of $x * b$ is $\left[N / p_{k},(N+1) / p_{k}\right)$.

Lemma 5.10. For the generalized Walsh functions $\left\{\psi_{n}\right\} \equiv W\left\{n_{i}\right\}$ as defined in [22], but indexed from 1 to $\infty$ rather than from 0 to $\infty$, we bave for $n=1,2,3$, $\ldots$ and any fixed $b$

$$
\psi_{n}(x * b)=\psi_{n}(x) \psi_{n}(b) \quad \text { for almost every } x \in[0,1]
$$

Proof. Let $\phi_{n}(x) \equiv \phi_{n-1}, n=1,2, \ldots$, where the $\phi_{n-1}$ are as defined in [22], i.e. indexed from to 1 to $\infty$. Assume $b$ and $x$ are as defined in the proof of Lemma 5.9. Then (also using imaginary $i$ )

$$
\phi_{n}(x) \phi_{n}(b)=\omega_{k}^{i} \cdot \omega_{k}^{j} \text { where } \omega_{k}=\exp \left(2 \pi i / n_{k}\right) .
$$

Also, since $\omega_{k}$ is of order $n_{k}$,

$$
\begin{aligned}
\phi_{n}(x * b) & =\phi_{n}\left\{\left[(i+j) \bmod n_{k}\right] / p_{k}+\sum_{i=k+1}^{\infty}\left[\left(x_{i}+b_{i}\right) \bmod n_{i}\right] / p_{i}\right\} \\
& =\omega_{k}^{(i+j) \bmod n_{k}}=\omega_{k}^{i+j} .
\end{aligned}
$$


Lemma 5.11. For the generalized Walsh functions in Lemma 5.10 we have

$$
\psi_{n}(b) \int_{0}^{1} f(x) \overline{\psi_{n}(x)} d x=\int_{0}^{1} f(x * b) \overline{\psi_{n}(x)} d x .
$$

Proof. By Lemmas 5.9 and 5.10

$$
\int_{0}^{1} f(x * b) \overline{\psi_{n}(x)} d x=\psi_{n}(b) \int_{0}^{1} f(x * b) \overline{\psi_{n}(x * b)} d x=\psi_{n}(b) \int_{0}^{1} f(x) \overline{\psi_{n}(x)} d x .
$$

Remark 5.2. Lemmas 5.9-5.11 were noted by H. Chrestenson [6] (cf. [29, p. 238]) for the case $n_{i} \equiv \alpha$ for $\alpha \in\{2,3,4, \ldots\}$. The group theoretic approach may also be easily used to prove these.

Lemma 5.12. For the system $W\left\{n_{i}\right\}$ we have $\Omega_{p}\left(f, 1 / p_{k}\right) \leq 2 E_{p}\left(f, p_{k}\right)$.

Proof. If $0<b \leq 1 / p_{k^{2}}$ then by Lemmas 5.9 and 5.10

$$
\begin{aligned}
\|f(x * b)-f(x)\|_{p} & =\|f(x)-P(x)+P(x * b)-f(x * b)\|_{p} \\
& \leq\|f(x)-P(x)\|_{p}+\|f(x)-P(x)\|_{p}
\end{aligned}
$$

if $P(x)$ is a Walsh type polynomial of degree not greater than $p_{k}$.

Lemma 5.13. For the system $W\left\{n_{i}\right\}$ we have, for $p \geq 1, E_{p}\left(f, p_{k}\right) \leq \Omega_{p}\left(f, 1 / p_{k}\right)$.

Proof. Using Lemmas 5.9 and 5.10, the notation of [22, p. 422], and the fact that [22, Equation (24), p. 422] $D_{p_{k}}(u)=p_{k} X\left[0,1 / p_{k}\right)(u)$ where $X$ is the characteristic function, we obtain

$$
\begin{aligned}
E_{p}\left(f, p_{k}\right) & \leq\left\|f(x)-S_{p_{k}}(f, x)\right\|_{p}=\left\{\int_{0}^{1}\left|f(x)-\int_{0}^{1} f(x * u) D_{p_{k}}(u) d u\right|^{p} d x\right\}^{1 / p} \\
& \leq\left\{\int_{0}^{1}\left[\int_{0}^{1}|f(x * u)-f(x)| D_{p_{k}}(u) d u\right]^{p} d x\right\}^{1 / p} \\
& \leq\left\{\int_{0}^{1} \int_{0}^{1}|f(x * u)-f(x)|^{p}\left[D_{p_{k}}(u)\right]^{p} d x d u\right\}^{1 / p} \\
& \leq\left\{\int_{0}^{1}\left[D_{p_{k}}(u)\right]^{p}\left[\Omega_{p}\left(f, 1 / p_{k}\right)\right]^{p} d u\right\}^{1 / p}=\Omega_{p}\left(f, 1 / p_{k}\right) .
\end{aligned}
$$

Remark 5.3. The proofs of Lemmas 5.12 and 5.13 are similar to those of Watari [30, Lemma 4] for the Walsh system.

Lemma 5.14. For the system $W\left\{n_{i}\right\}$ assume $f \in L^{p}[0,1]$ and $f$ is of period 1 (and as always that $\left\{n_{i}\right\}$ is bounded). Then, for $p \geq 1, \Omega_{p}\left(f, 1 / p_{k}\right)=$ $O\left[\omega_{p}\left(f, 1 / p_{k}\right)\right]:$

Proof. Assume $0<b \leq 1 / p_{k}$ and $x \in\left[i / p_{k},(i+1) / p_{k}\right)$. Then 


$$
x=N n_{k} / p_{k}+\left[i\left(\bmod n_{k}\right)\right] / p_{k}+\sum_{i=k+1}^{\infty} x_{i} / p_{i}
$$

and

$$
x * b=N n_{k} / p_{k}+\left[\left(i+b_{k}\right) \bmod n_{k}\right] / p_{k}+\sum_{i=k+1}^{\infty}\left[\left(x_{i}+b_{i}\right) \bmod n_{i}\right] / p_{i}
$$

Hence,

$$
|(x * b)-x| \leq\left(n_{k}-1\right) / p_{k} \equiv \delta
$$

Consequently

$$
\begin{aligned}
\Omega_{p}\left(f, 1 / p_{k}\right) \leq & \sup _{0<b \leq \delta}\left\{\int_{0}^{1}|f(x+b)-f(x)|^{p} d x\right\}^{1 / p} \\
& +\sup _{0<b \leq \delta}\left\{\int_{0}^{1}|f(x-b)-f(x)|^{p} d x\right\}^{1 / p} \\
\leq & 2\left(n_{k}-1\right) \omega_{p}\left(f, 1 / p_{k}\right)=O\left[\omega_{p}\left(f, 1 / p_{k}\right)\right] .
\end{aligned}
$$

Remark 5.4. Lemma 5.14 was noted for $W$ by McLaughlin [19, proof of Theorem 7].

6. The trigonometric, Walsh, and generalized Walsh system.

Theorem 6.1. Assume $0<\beta \leq p, \varphi(k)$ is a quasi-monotone sequence, $\left\{m_{n}\right\}$ is an increasing sequence of positive integers, and $\left\{b_{k}\right\}$ is a sequence of real or complex numbers. Assume there exist constants $k$ and $N$ such that

$$
1<k \leq m_{n+1} / m_{n} \leq N \text { for } n \text { sufficiently large }
$$

and also

$$
\left(\sum_{k=m_{n}+1}^{m_{n+1}}\left|b_{k}\right|^{p}\right)^{1 / p}=O\left[\varphi\left(m_{n}\right)\right]
$$

If $\Sigma_{k=1}^{\infty} k^{\gamma-\beta / p}[\varphi(k)]^{\beta}<\infty$, then $\Sigma_{k=1}^{\infty}\left|b_{k}\right|^{\beta} k^{\gamma}<\infty$ for $\gamma$ real.

Proof. By Hölder's inequality

$$
\begin{aligned}
\sum_{k=m_{n}+1}^{m}\left|b_{k}\right|^{\beta} & \leq\left(\sum_{k=m_{n}+1}^{m}\left|b_{k}\right|^{p}\right)^{\beta / p}\left(\sum_{k=m_{n}+1}^{m_{n+1}} 1\right)^{1-\beta / p} \\
& =0\left\{\left[\varphi\left(m_{n}\right)\right]^{\beta}\left[m_{n+1}-m_{n}\right]^{1-\beta / p}\right\} .
\end{aligned}
$$


Also (6.1) implies that $\left(m_{n}-m_{n-1}\right) / m_{n}=1-m_{n-1} / m_{n} \geq 1-1 / k>0$ and also that $\left(m_{n+1}-m_{n}\right) /\left(m_{n}-m_{n-1}\right) \leq[N-1] /[1-1 / k]=O(1)$.

Hence,

$$
\begin{aligned}
\sum_{k=m_{n}+1}^{m_{n+1}}\left|b_{k}\right|^{\beta} \cdot k^{\gamma} & =O\left\{\left[\varphi\left(m_{n}\right)\right]^{\beta}\left[m_{n}-m_{n-1}\right]\left[m_{n}-m_{n-1}\right]^{-\beta / p}\left[m_{n}\right]^{\gamma}\right\} \\
& =O\left\{\left[\varphi\left(m_{n}\right)\right]^{\beta}\left[m_{n}\right]^{\gamma-\beta / p}\left[m_{n}-m_{n-1}\right]\left[\left(m_{n}-m_{n-1}\right) / m_{n}\right]^{-\beta / p}\right\} \\
& =O\left\{\left[\varphi\left(m_{n}\right)\right]^{\beta}\left[m_{n}\right]^{\gamma-\beta / p}\left[m_{n}-m_{n-1}\right]\right\} .
\end{aligned}
$$

Therefore, our result follows from Lemma 4.5, since (4.1) is satisfied. (6.1). If

Theorem 6.2. Assume $\left\{\varphi_{k}\right\}$ is $O N$ on $[a, b], 1 / p+1 / q=1$, and $\left\{m_{n}\right\}$ satisfies

$$
S_{q}\left(m_{n}, m_{n+1}\right)=O\left[E_{p}\left(f, m_{n}\right)\right], \quad 1<p \leq 2,
$$

and for $p=1$

$$
\left|a_{k}\right|=O\left[E_{1}(f, k-1)\right],
$$

then for $1 \leq p \leq 2$ and $0<\beta \leq q$ we have (1.1) satisfied if

$$
\sum_{k=1}^{\infty} k^{\gamma-\beta / q}\left[E_{p}(f, k)\right]^{\beta}<\infty \text {. }
$$

Proof. Immediate by Theorem 6.1.

Theorem 6.3. Assume $\left\{\varphi_{k}\right\}$ is $O N$ on $[a, b], 1 / p+1 / q=1$, and $\left\{m_{n}\right\}$ satisfies. (6.1). If

$$
S_{q}\left(m_{n}, m_{n+1}\right)=O\left[\omega_{p}\left(f, 1 / m_{n}\right)\right] \text { for } 1<p \leq 2
$$

and for $p=1$

$$
\left|a_{k}\right|=O\left[\omega_{1}\left(f, k^{-1}\right)\right]
$$

then for $1 \leq p \leq 2$ and $0<\beta \leq q$ we have (1.1) satisfied whenever

$$
\sum_{k=1}^{\infty} k^{\gamma-\beta / q}\left[\omega_{p}\left(f, k^{-1}\right)\right]^{\beta}<\infty \text {. }
$$

Theorem 6.4. For the system $W$ and more generally $W\left\{n_{i}\right\}$, we bave (6.3) and (6.4) as well as (6.6) and (6.7) satisfied.

Proof. By Lemma 5.11, $a_{k} \psi_{k}(b)=\int_{0}^{1} f(x * b) \overline{\psi_{k}(x)} d x$ for the system $W\left\{n_{i}\right\}$. Thus, by Riesz's Lemma 4.18 we have for $1 \leq p \leq 2$ (and indexing from 1 to $\infty$ )

$$
\left(\sum_{k=1}^{\infty}\left|a_{k}\left[1-\psi_{k}(b)\right]\right|^{q}\right)^{1 / q} \leq\left\{\int_{0}^{1}|f(x * b)-f(x)|^{p} d x\right\}^{1 / p}
$$


Setting $b=1 / p_{k+1}$, we obtain $\psi_{n}\left(1 / p_{k+1}\right)=\omega_{k}$ for $p_{k}<n \leq p_{k+1}$. Thus $\left|1-\psi_{n}\left(1 / p_{k+1}\right)\right|=\left|1-\exp \left(2 \pi i / n_{k}\right)\right| \geq c>0$ for $p_{k}<n \leq p_{k+1}$. Hence,

$$
s_{q}\left(p_{k}, p_{k+1}\right)=0\left\{\int_{0}^{1}\left|f\left(x * p_{k}^{-1}\right)-f(x)\right|^{p} d x\right\}^{1 / p} .
$$

And this implies that

$$
S_{q}\left(p_{k}, p_{k+1}\right)=O\left[\Omega_{p}\left(f, 1 / p_{k}\right)\right], \quad 1 \leq p \leq 2 .
$$

For $p=1$, this implies $a_{k}=O\left[\Omega_{1}\left(f, k^{-1}\right)\right]$. Hence our result follows from Lemmas 5.12 and 5.14 .

In fact we have just proved the following.

Theorem 6.5. For $W\left\{n_{i}\right\}$ if $1 \leq p \leq 2,0<\beta \leq q$, and $1 / p+1 / q=1$, then (1.1) is satisfied if

$$
\left.\sum_{k=1}^{\infty} k^{\gamma-\beta / q\left[\Omega_{p}\right.}\left(f, k^{-1}\right)\right]^{\beta}<\infty .
$$

Remark 6.1. The conclusion of Theorem 6.3 was proved by Konyushkov [17, p. 81] with respect to $T$ for $1<p \leq 2$ and for the case $p=1$ is known and easily proved (compare [2, II, p. 197]).

Remark 6.2.W $\left.W n_{i}\right\}$ may be interpreted as the full set of characters of the countable direct product of cyclic groups of arbitrary bounded order $n_{i}, n_{i} \geq 2$ [22]. C. Onneweer [20, Theorem 1] has proved a result via the group approach about $W\left\{p_{n}\right\}$ for $\left\{p_{n}\right\}$ also prime (and bounded). Whether $\left\{n_{i}\right\}$ is prime or not appears to make no essential difference. The boundedness of $\left\{n_{i}\right\}$ is, however, essential [22].

Remark 6.3. We will eventually show that all known (to the author) sufficiency conditions for absolute convergence for $T, W$, or $W\left\{n_{i}\right\}$ given in terms of Lip $a$, Lip $(\alpha, p), \operatorname{Var} p, \omega_{p}(f, \delta)$, etc. follow from (6.8) (or from the more powerful (6.9)) and most for the case $p=q=2$. This important special case will be considered in $\$ 8$. However, we shall not deal with the second order $\omega_{p}^{(2)}(f, \delta)$ as defined in [8, p. 290].

Theorem 6.6. Assume an ON system satisfies (6.6) and (6.7) for $\left\{m_{n}\right\}$ satis. fying (6.1). If $f \in \operatorname{Lip}(\alpha, p)$ for some $0<\alpha \leq 1$ and $1 \leq p \leq 2$, then (1.2) is satis. fied for

$$
\beta>p /[p(1+\alpha)-1] \text { and } \gamma<\alpha-1 / p \text {. }
$$

Proof. Part (a). $\left[\omega_{p}\left(f, k^{-1}\right)\right]^{\beta} k^{-\beta / q}=O\left[k^{-\beta(a+1 / q)}\right]$. Thus, we need $\beta(\alpha+1-1 / p)>1$ or $\beta>p /[p(1+\alpha)-1]$.

Part (b). $\omega_{p}\left(f, k^{-1}\right) k^{\gamma-1+1 / p}=O\left[k^{\gamma-1+1 / p-\alpha}\right]$. Hence, we need $\gamma-a+$ $1 / p<0$ or $\gamma<\alpha-1 / p$. 
Remark 6.4. Theorem 6.4 generalizes Theorem 3.10. The second part of Theorem 6.6 is known for $T$ [34, I, Problem 9, p. 251]. We will give an easier proof of Theorem 6.6 for $p=2$ in $\$ 8$.

Theorem 6.7. Assume an $O N$ system satisfies (6.6) and (6.7) for $\left\{m_{n}\right\}$ satisfying (6.1). If $f \in \operatorname{Var} p, 0<p<1$, and $f \in$. Lip $a, 0<a \leq 1$, then (1.2) is satis. fied for

$$
\beta>1 /[\alpha(1-p)+1] \text { and } \gamma<\alpha(1-p) .
$$

Proof. Part (a). By Lemma 5.3

$$
\left[\omega_{1}\left(f, k^{-1}\right)\right]^{\beta}=O\left\{\left[\omega_{p}\left(f, k^{-1}\right)\right]^{p}\left[\omega\left(f, k^{-1}\right)\right]^{1-p}\right\}^{\beta}=O\left[k^{-1-a(1-p)}\right]^{\beta} .
$$

Part (b). $\omega_{1}\left(f, k^{-1}\right) k^{\gamma}=O\left[k^{\gamma-1-a(1-p)}\right]$.

Remark 6.5. Conditions (6.6) and (6.7) (or Conditions (6.3) and (6.4)) were needed in these proofs of Theorems 6.6 and 6.7 to obtain the desired strength. Hence, in $\$ 7$, we will investigate more closely these conditions. Theorem 6.7 is new.

7. Uniformly bounded orthonormal systems.

Theorem 7.1. If $\left\{\varphi_{k}\right\}$ is a BON system in $L^{2}(\mu)$, then

$$
\left.s_{q}(n, \infty)=O\left\|f-S_{n}(f)\right\|_{p}\right) \text { if } 1<p \leq 2
$$

and

$$
\left|a_{n+1}\right|=O\left(\left\|f-s_{n}(f)\right\|_{1}\right) \text { for } p=1 .
$$

Proof. By Riesz's Lemma 4.18 we have

$$
s_{q}(n, \infty)=O\left(\left\|f-\sum_{1}^{n} a_{k} \varphi_{k}\right\|_{p}\right)=O\left(\left\|f-s_{n}(f)\right\|_{p}\right) .
$$

Theorem 7.2. If $\left\{\varphi_{k}\right\}$ is a SBON system on $[a, b]$ for some $p, 1 \leq p \leq 2$, then (6.3) and (6.4) are satisfied for that $p$.

Proof. By Lemmas 4.11 and 4.12, $\left\|f-S_{n}(f)\right\|_{p}=O\left[E_{p}(f, n)\right]$.

Theorem 7.3. If $\left\{\varphi_{n}\right\}$ is a BON system on $[a, b]$ which for some $p, 1 \leq p \leq$ 2, satisfies

$$
\left\|f-S_{n}(f)\right\|_{p}=O\left[\omega_{p}\left(f, n^{-1}\right)\right]
$$

then (6.6) and (6.7) are satisfied for that $p$.

Proof. Immediate by Theorem 7.1.

Remark 7.1. By Theorem 7.2, Lemmas 4.6, 4.13, 4.14 and 4.15 we obtain an alternate proof of Theorem 6.4 for the systems $W$ and $T$ if $1<p \leq 2$. For the case $p=1$, this proof does not suffice, since it is not true that 


$$
\left\|f-S_{n}(f)\right\|_{1}=o(1)
$$

for $T$ or $W$ as is well known.

Theorem 7.4. If $\left\{\varphi_{k}\right\}$ is a SBON system on $[a, b]$ for some $p, 1 \leq p \leq 2$, $1 / p+1 / q=1$, and $0<\beta \leq q$, then (1.1) is valid whenever

$$
\sum_{k=1}^{\infty} k^{\gamma-\beta / q}\left[E_{p}(f, k)\right]^{\beta}<\infty .
$$

Proof. Immediate by Theorems 6.2 and 7.2.

Remark 7.2. In 1947 S. B. Stechkin [23, Theorem 1] announced that the conclusion of Theorem 7.4 was valid for $\gamma=0$ and $1<p \leq 2$ for every BON system on $[0,2 \pi]$. I am unable to find the proof of Stechkin's assertion in the literature and so cannot guarantee its authenticity.

Remark 7.3. Theorems 7.2, 7.3 and 7.4 could, of course, be given in a more general setting for BON systems in $L^{2}(\mu)$ where $(X, A, \mu)$ is a measure space.

8. General orthonormal systems.

Theorem 8.1. For every $O N$ system $\left\{\varphi_{k}\right\}$, assume that $\{m(k)\}$ is an increasing sequence of natural numbers and $0<\beta \leq 2$.

$$
\text { If } \sum_{k=1}^{\infty} k^{\gamma-\beta / 2}\left[E_{2}(f, m(k))\right]^{\beta}<\infty \text {, then } \sum_{k=1}^{\infty}\left|a_{m(k)}\right|^{\beta} k^{\gamma}<\infty
$$

where $\left\{a_{k}\right\}$ denotes, as usual, the Fourier coefficients of $/$ for $\left\{\varphi_{k}\right\}$.

Proof. By Bessel's inequality

$$
\begin{aligned}
\left(\sum_{k=2^{n}+1}^{2^{n+1}}\left|a_{m(k)}\right|^{2}\right)^{1 / 2} & \leq\left(\sum_{k=2^{n}+1}^{\infty}\left|a_{m(k)}\right|^{2}\right)^{1 / 2} \leq\left(\sum_{k=m\left(2^{n}+1\right)}^{\infty}\left|a_{k}\right|^{2}\right)^{1 / 2} \\
& \leq\left\|f-S_{m\left(2^{n}+1\right)-1}(f)\right\|_{2} \leq E_{2}\left(f, m\left(2^{n}\right)\right)
\end{aligned}
$$

and so our result follows from Theorem 6.1 with $p=2$.

Theorem 8.2. If an ON system satisfies (1.3), then we may replace $E_{2}(f, m(k))$ in Theorem 8.1 by $\omega_{2}(f, 1 / m(k))$.

Remark 8.1. Theorem 8.1 is a generalization of Stechkin's Theorem 3.15. Also Theorem 8.2 is a generalization of [24, Theorem 4]. More exact bounds as in Theorem 3.15 could be obtained if desired.

Theorem 8.3. For an $O N$ system, if $0<\beta \leq 2$, then (1.1) is satisfied whenever 


$$
\sum_{k=1}^{\infty} k^{\gamma-\beta / 2}\left[E_{2}(f, k)\right]^{\beta}<\infty
$$

Theorem 8.4. For an $O N$ system, if $0<\beta \leq 2$ and (1.3) is satisfied, then (1.1) is satisfied whenever

$$
\sum_{k=1}^{\infty} k^{\gamma-\beta / 2}\left[\omega_{2}\left(f, k^{-1}\right)\right]^{\beta}<\infty .
$$

Remark 8.2. The systems $T, W, W\left\{n_{i}\right\}, H, F$, and $H\left\{n_{i}\right\}$ satisfy (1.3) as Lemmas 4.13, 5.13, and 5.14 show. Also Wik's Theorem 3.11 (as well as [32, Theorem 8.1 (first part)]) is true for every ON system satisfying (1.3), since the only result concerning $\mathrm{ON}$ systems in Wik's proof was the fact that

$$
\sum_{k=1}^{\infty} k^{-1 / 2} \omega_{2}\left(f, k^{-1}\right)<\infty \text { implies } f \in A \text {. }
$$

Of course, all of the sufficiency conditions that follow from (8.4) are true for all ON systems satisfying (8.4) (see [2, II, pp. 154-161]). For example, if $f$ is absolutely continuous and $f^{\prime} \in L^{p}, p>1$, then $f \in A$ is valid for these systems. Theorem 3.4 shows that the result stated in the preceding sentence is best possible for every $\mathrm{CBON}$ system on $[0,1]$.

Remark 8.3. C. Onneweer [20, Corollary 1] has essentially proved that (8.4) is true for $W\left\{n_{i}\right\}$, for $\left\{n_{i}\right\}$ additionally prime. His proof, however, required the use of Riesz's Lemma 4.18. It should be noted here that $f \epsilon \operatorname{Lip} a$ "on the group" does not imply that $f \in \operatorname{Lip} \alpha$ on $[0,1]$, but the converse is true [28, p. 12]. My Theorem 6.5 essentially generalizes this result of Onneweer (as well as his Corollary 2, Theorem 2, and Theorem 3 in [20]). Theorem 3.12, of course, refers to (8.4).

Remark 8.4. S. Banach has proved [1, p. 100] that there is a continuum of ON systems such that the Fourier series of every differentiable function is divergent almost everywhere.

Theorem 8.5. Assume an $O N$ system satisfies (8.4) (or (1.3)) and $f \in \operatorname{Var} p$, $0<p<2$. Then

$$
\sum_{k=1}^{\infty} k^{-1}\left[\omega\left(f, k^{-1}\right)\right]^{1-p / 2}<\infty \text { implies } f \in A .
$$

Proof. By Lemmas 4.4 and 5.3

$$
\omega_{2}\left(f, k^{-1}\right)=O\left\{\left[\omega\left(f, k^{-1}\right)\right]^{1-p / 2} \cdot k^{-1 / 2}\right\}
$$

Our result is now immediate.

Remark 8.5. Theorem 8.5 generalizes Theorem 3.17 to the systems $T, W$, 
etc. Also, Theorem 8.5 generalizes Theorem 3.7. For $0<p<1$ it is new.

Theorem 8.6. If an $O N$ system satisfies $(1.3)$ and $f \in \operatorname{Lip}(\alpha, 2)$ for some $0<$ $\alpha \leq 1$, then (1.1) is satisfied whenever $0<\beta \leq 2$ and

$$
\beta\left(\alpha+\frac{1}{2}\right)>1+\gamma \text {. }
$$

Proof. Using Theorem 8.4 we find

$$
\sum_{k=1}^{\infty} k^{\gamma-\beta / 2}\left[\omega_{2}\left(f, k^{-1}\right)\right]^{\beta}=O\left[\sum_{k=1}^{\infty} k^{\gamma-\beta / 2-\alpha \beta}\right] \text {. }
$$

Hence, we need $\beta(\alpha+1 / 2)-\gamma>1$.

Corollary 8.1. If an $O N$ system satisfies (1.3) and $f \in \operatorname{Lip}(\alpha, 2)$ for some 0 $\alpha \leq 1$, then (1.2) is satisfied for $0<\beta \leq 2$ whenever

$$
\beta>2 /(2 \alpha+1) \text { and } y<\alpha-1 / 2 \text {. }
$$

Theorem 8.7. If an $O N$ system satisfies (1.3) and $f \in \operatorname{Var} p, p \geq 2$, then (1.1) is satisfied for $0<\beta \leq 2$ and

$$
\beta(1 / p+1 / 2)>1+\gamma
$$

Proof. By Lemmas 4.1 and 4.4

$$
k^{\gamma-\beta / 2}\left[\omega_{2}\left(f, k^{-1}\right)\right]^{\beta}=O\left\{k^{\gamma-\beta / 2}\left[\omega_{p}\left(f, k^{-1}\right)\right]^{\beta}\right\}=\alpha\left\{k^{\gamma-\beta / 2-\beta / p}\right\} .
$$

Hence, by Theorem 8.4, we need $\beta(1 / p+1 / 2)-\gamma>1$.

Corollary 8.2. If an $O N$ system satisfies (1.3) and $f \in \operatorname{Var} p, p \geq 2$, then (1.2) is satisfied for $0<\beta \leq 2$ whenever

$$
\beta>2 p /(2+p) \text { and } \gamma<1 / p-1 / 2 \text {. }
$$

Remark 8.6. Corollary 8.2 generalizes Theorem 3.13 .

Theorem 8.8. If an ON system satisfies (1.3) and $f \in \operatorname{Lip}$ a for some $0<\alpha \leq$ 1 , then (1.1) is satisfied whenever $0<\beta \leq 2$ and

$$
\beta(\alpha+1 / 2)>1+\gamma \text {. }
$$

Proof. By Lemmas 4.1 and 4.4

$$
k^{\gamma-\beta / 2}\left[\omega_{2}\left(f, k^{-1}\right)\right]^{\beta}=O\left\{k^{\gamma-\beta / 2-\alpha \beta}\right\} \text {. }
$$

Hence, by Theorem 8.4 we need $\beta(\alpha+1 / 2)-\gamma>1$.

Corollary 8.3. If an $O N$ system satisfies (1.3) and $f \in \operatorname{Lip} \alpha$ for some $0<\alpha \leq$ 1 , then (1.2) is satisfied for $0<\beta \leq 2$ whenever

$$
\beta>2 /(2 \alpha+1) \text { and } \gamma<\alpha-1 / 2 \text {. }
$$

Remark 8.7. Corollary 8.3 generalizes Theorem 3.1. Also, the inequalities 
(8.11) in Corollary 8.3 may not be improved for any CON system on $[0,1]$ as Theorem 3.2 illustrates if $0<a<1$. Onneweer [20, Theorems 2 and 3] has essentially proved that Corollary 8.3 is valid for the system $W\left\{p_{n}\right\}$. My Lemmas 5.13 and 5.14 (or my stronger Theorem 6.5 ) unify and yield an alternate proof of his results (Theorems 2 and 3 in [20]).

Theorem 8.9. If an ON system satisfies (1.3), $f \in$ Var $p$ for some $0<p<2$, and $f \epsilon \operatorname{Lip} \alpha$ for $\alpha>0$, then (1.1) is satisfied for $0<\beta \leq 2$ and

$$
\beta[\alpha(1-p / 2)+1]>1+\gamma .
$$

Proof. By Lemmas 4.4 and 5.3

$$
\begin{aligned}
k^{\gamma-\beta / 2}\left[\omega_{2}\left(f, k^{-1}\right)\right]^{\beta} & \leq k^{\gamma-\beta / 2}\left\{\left[\omega\left(f, k^{-1}\right)\right]^{1-p / 2}\left[\omega_{p}\left(f, k^{-1}\right)\right]^{p / 2}\right\}^{\beta} \\
& =O\left\{k^{\gamma-\beta / 2}\left[k^{-a(1-p / 2)-1 / 2}\right]^{\beta}\right\} .
\end{aligned}
$$

Hence, by Theorem 8.4, we need $\beta[\alpha(1-p / 2)+1]-\gamma>1$.

Corollary 8.4. If an ON system satisfies (1.3), $f \in \operatorname{Var} p$ for some $0<p<2$, and $f \in \operatorname{Lip} \alpha$, for $\alpha>0$, then (1.2) is sat isfied for $0<\beta \leq 2$ whenever

$$
\beta>2 /[\alpha(2-p)+2] \text { and } \gamma<\alpha(1-p / 2) \text {. }
$$

Corollary 8.5. If an $O N$ system satisfies (1.3) and $f \epsilon \operatorname{Lip} a$ for some $a>0$ and also $f \in$ Var $p$ for some $0<p<2$, then $f \in A$.

Proof. Immediate by Corollary $\mathbf{8 . 4}$.

Remark 8.8. By Bočkarev's Theorem 3.6, Corollary 8.4 is best possible in a certain sense for every $\mathrm{CBON}$ on $[0,1]$. Corollary 8.4 generalizes Theorem 3.5. Corollary 8.5, of course, generalizes Theorems 3.3 and 3.8 to a broader class of ON systems. Onneweer [20, Corollary 3] has also proved a group analogue of Theorem 3.8 for the system $W\left\{n_{i}\right\}$, for $\left\{n_{i}\right\}$ additionally prime, by utilizing Riesz's Lemma 4.18.

Theorem 8. 10. If $f \in \operatorname{Var} r, 1 \leq s<\infty, 1<p<\infty, 1 / p+1 / q=1$, and $1 \leq r<$ $s p$, then

$$
\sum_{k=1}^{\infty} k^{-1 / 2} \omega_{s}\left(f, k^{-1}\right)=0\left\{\sum_{k=1}^{\infty} k^{-1 / 2-1 / s p}\left[\omega_{r+(s-r) q}\left(f, k^{-1}\right)\right]^{1-r / s p}\right\} .
$$

Proof. Immediate by Lemma 5.2.

Theorem 8.11. Assume an ON system satisfies (8.4) (or (1.3)) and $1<p<\infty$, $1 / p+1 / q=1,1 \leq r<2 p$. If $/ \in \operatorname{Var} r$, then

$$
\sum_{k=1}^{\infty} k^{-1+1 / 2 q}\left[\omega_{r+(2-r) q}\left(f, k^{-1}\right)\right]^{1-r / 2 p}<\infty \text { implies } f \in A .
$$


Proof. Set $s=2$ in Theorem 8.10 and apply Theorem 8.4 (or Conditions (8.4) or (1.3)).

Remark 8.9. Theorem 8.11 generalizes Theorem 3.9 to all ON systems satisfying (8.4) (or (1.3)).

9. The Haar, Franklin, and generalized Haar system.

Theorem 9.1. For any real or complex sequence of bounded ON functions $\left\{\varphi_{k}\right\}$ in the Banach space $L^{2}(\mu)$, where $(X, A, \mu)$ is a measure space, let $\left\{a_{k}\right\}$ denote (as usual) the Fourier coefficients of / (real or complex). Then if $1 \leq p \leq$ $\infty$, we have for $m>n$ (using Definitions 2.18 and 2.19) and $1 / p+1 / q=1$

$$
S_{p}(n, m) \leq\left\|\sum_{k=n+1}^{m} a_{k} \varphi_{k}\right\|_{p} \Phi_{p}(n, m) .
$$

Proof. Following a technique of Ciesielski [8, p. 308], we set

Then

$$
c_{n}=\left|a_{n}\right|^{p-1} \exp \left\{-i \theta_{n}\right\} \text { where } a_{n}=\left|a_{n}\right| \exp \left\{i \theta_{n}\right\}
$$

$$
\begin{aligned}
\sum_{k=n+1}^{m}\left|a_{k}\right|^{p} & =\left|\sum_{k=n+1}^{m} a_{k} c_{k}\right| \leq\left\|\sum a_{k} \varphi_{k}\right\|_{p}\left\|\sum c_{k} \varphi_{k}\right\|_{q} \\
& \leq\left\|a_{k} \varphi_{k}\right\|_{p} \Phi_{p}(n, m)\left(\sum\left|a_{k}\right|^{p}\right)^{1 / q}
\end{aligned}
$$

by Lemmas 4.9 and 5.8. Hence,

$$
\left(\sum_{k=n+1}^{m}\left|a_{k}\right|^{p}\right)^{1-1 / q} \leq\left\|\sum a_{k} \varphi_{k}\right\|_{p} \cdot \Phi_{p}(n, m) .
$$

Theorem 9.2. Under the bypothesis of Theorem 9.1 we bave

$$
S_{p}(n, m) \leq\left(\left\|f-S_{n}(f)\right\|_{p}+\left\|f-S_{m}(f)\right\|_{p}\right) \Phi_{p}(n, m) .
$$

Proof. The proof is immediate by Lemma 4.10 and Theorem 9.1.

Theorem 9.3. Assume the bypothesis of Theorem 9.1 and also that $\left\{\varphi_{k}\right\}$ is a SON system for some $p, 1 \leq p \leq \infty$. Then for any increasing sequence of integers $\left\{m_{n}\right\}$ we have

$$
S_{p}\left(m_{n}, m_{n+1}\right)=O\left[E_{p}\left(f, m_{n}\right) \Phi_{p}\left(m_{n}, m_{n+1}\right)\right] .
$$

Proof. Immediate by Lemma 4.12 and Theorem 9.2.

Theorem 9.4. Assume the bypothesis of Theorem 9.1, that $\left\{\varphi_{k}\right\}$ is a SON system for some $p, 1 \leq p \leq \infty$, and that $\left\{m_{n}\right\}$ is an increasing sequence of integers satisfying (6.1). Suppose also that $\varphi(k)$ is a quasi-monotone sequence satisfying 


$$
\Phi_{p}\left(m_{n}, m_{n+1}\right)=O\left[\varphi\left(m_{n}\right)\right]
$$

If $0<\beta \leq p, \gamma$ real, then $(1.1)$ is satisfied for $\left\{\varphi_{k}\right\}$ whenever

$$
\sum_{k=1}^{\infty} k^{\gamma-\beta / p}[\varphi(k)]^{\beta}\left[E_{p}(f, k)\right]^{\beta}<\infty .
$$

Proof. Apply Theorems 6.1 and 9.3.

Theorem 9.5. If $\beta>0, \gamma \geq 0$, then (1.1) is satisfied for the systems $H, F$, and $H\left\{n_{i}\right\}$ whenever

$$
\sum_{k=1}^{\infty} k^{\gamma-\beta / 2}\left[E_{\mu}(f, k)\right]^{\beta}<\infty \quad \text { where } \mu=\max (\beta, 1) \text {. }
$$

Proof. By Lemma 4.7 these are SON systems for $1 \leq p \leq \infty$.

If $\beta \geq 1$ for $H$ or $F$ apply Theorem 9.4 with $\beta=p$, Lemmas 4.19 and 5.5. If $\beta \geq 1$ for $H\left\{n_{i}\right\}$ apply Theorem 9.4 with $\beta=p$ and Lemma 5.7.

To extend to the case $0<\beta<1$, apply the technique given in the proof of Lemma 5.4.

Remark 9.1. Applying Lemma 4.8, Theorem 6.1, and Theorem 9.3, one could obtain a result for $H\left\{n_{i}\right\}$ for $\left\{n_{i}\right\}$ unbounded and $1<\beta<\infty$.

Corollary 9.1. If $\beta>0, \gamma \geq 0$, then (1.1) is satisfied for the systems $H, F$, and $H\left\{n_{i}\right\}$ whenever

$$
\sum_{k=1}^{\infty} k^{\gamma-\beta / 2}\left[\omega_{\mu}\left(f, k^{-1}\right)\right]^{\beta}<\infty \quad \text { where } \mu=\max (\beta, 1) \text {. }
$$

Proof. Immediate by Lemma 4.13 and Theorem 9.5.

Remark 9.2. Corollary 9.1 is a generalization of Theorem 3.16. It is new for $F$ and $H\left\{n_{i}\right\}$. This result for $H$ also follows from Theorem 6.1 and Lemma 4.16. The result for $H\left\{n_{i}\right\}$, for $\left\{n_{i}\right\}$ additionally assumed prime, also follows from Theo rem 6.1, Lemma 4.17, and Lemma 5.4. Also, the series in (9.6) and (9.7) for these systems probably converge or diverge simultaneously (see, for example $[8$, Theorem 13, p. 317]).

Remark 9.3. For the systems $H, F$, and $H\left\{n_{i}\right\}$ we have by Corollary 9.1 that

$$
\sum_{k=1}^{\infty} k^{-1 / 2} \omega_{1}\left(f, k^{-1}\right)<\infty \text { implies } f \in A .
$$

Since $\omega_{1}\left(f, k^{-1}\right) \leq \omega_{2}\left(f, k^{-1}\right)$ by Lemma 4.1 , this condition $(9.8)$ is a weaker condition than condition (8.4). Hence, any sufficiency result which depends upon the convergence of the series in (8.4) is automatically true for the systems $H, F$, etc. Thus, Tevzadze's announced Theorem 3.9 for the system $H$ is immediate, 
since the convergence of the series in (9.8) follows from the convergence of the series in (8.4). Of course, Ciesielski's Theorem 3.20 is generalized by (9.8).

Remark 9.4. Theorem 3.18 is a corollary of Theorem 3.19 (by Lemma 4.2). We will now show that Theorem 3.19 for $H$ follows from Theorem 3.16. Indeed, we use Corollary 9.1 to prove a generalization of Theorem 3.19.

Theorem 9.6. For the systems $H, F$, and $H\left\{n_{i}\right\}$ we bave that if $f \in \operatorname{Var} p, p \geq$ 1 , then (1.1) is satisfied for $0<\beta \leq p, \gamma \geq 0$, and

$$
\beta(1 / p+1 / 2)>1+\gamma \text {. }
$$

Proof. Case 1. If $1 \leq p \leq 2$ and $0<\beta \leq 1$, then we may assume $\mu=$ $\max (\beta, 1)=1$. Then

$$
k^{\gamma-\beta / 2}\left[\omega_{1}\left(f, k^{-1}\right)\right]^{\beta}=0\left\{k^{\gamma-\beta / 2}\left[\omega_{p}\left(f, k^{-1}\right)\right]^{\beta}\right\}=O\left\{k^{\gamma-\beta / 2-\beta / p}\right\} .
$$

Thus, we need $\beta(1 / 2+1 / p)-\gamma>1$ by Corollary 9.1 .

Case 2. If $p \geq 2$, we could apply Theorem 8.7 , or utilize the fact that we may assume that $\mu=\max (\beta, 1)=\beta$ and $\beta \leq p$ and proceed as in Case 1 to get

$$
k^{\gamma-\beta / 2}\left[\omega_{\beta}\left(f, k^{-1}\right)\right]^{\beta}=O\left\{k^{\gamma-\beta / 2}\left[\omega_{p}\left(f, k^{-1}\right)\right]^{\beta} .\right.
$$

Corollary 9.2. For the systems $H, F$, and $H\left\{n_{i}\right\}$ we bave that if $f \in \operatorname{Var} p$, $p \geq 1$, then (1.2) is satisfied for $B>0, \gamma \geq 0$ whenever

$$
\beta>2 p /(2+p) \text { and } \gamma<1 / p-1 / 2 \text {. }
$$

Proof. If $1 \leq p<2$, then $2 p /(2+p)<1$, and so we may assume $\beta \leq 1$. If $p \geq$ 2 , then we may assume that $\beta \leq 2$.

Theorem 9.7. For the systems $H, F, H\left\{n_{i}\right\}$, or any system satisfying (9.8) we bave that if $1<p<\infty, 1 / p+1 / q=1,1 \leq r<p$, and $f \in \operatorname{Var} r$, then

$$
\sum_{k=1}^{\infty} k^{-1 / 2-1 / p}\left[\omega_{r+(1-r) q}\left(f, k^{-1}\right)\right]^{1-r / p}<\infty \text { implies } f \in A .
$$

Proof. Set $s=1$ in Theorem 8.10 and apply Condition (9.8).

Remark 9.5. Theorem 9.7 generalizes Theorem 3.9 in scope and strength for Haar type systems.

Remark 9.6. For Haar series there is a great difference between absolute convergence of Fourier series and absolute convergence of the series of Fourier coefficients (see, for example [18]).

Remark 9.7. It may be of interest to note that for every ON system on $[0,1]$ we have

$$
\Phi_{1}(n, m) \geq(m-n)^{1 / 2}
$$


since we have (compare Remark 5.1)

$$
m-n=\int_{0}^{1} \sum_{k=n+1}^{m} \varphi_{k}^{2}(x) d x \leq \int_{0}^{1}\left(\sum \mid \varphi_{k}(x)\right)^{2} d x \leq\left\|\sum\left|\varphi_{k}(x)\right|\right\|_{\infty}^{2} .
$$

10. Concluding remarks. To completely understand the motivation for this paper, the reader should trace down the proofs of Theorems 3.1-3.20 (excluding the three necessary type results). Theorems $3.1,3.3,3.8$, or 3.9 are regularly being proved for different systems using various techniques. However, all of these results are corollaries of Theorem 3.12 which was done by Szász in 1948 for $T$. Similarly, Theorems 3.17, 3.18, and 3.19 are corollaries of Theorem 3.16 which was done by Ciesielski and Musielak in 1959 for $H$. In fact we have also demonstrated:

1. Theorems $3.1,3.3,3.5,3.7-3.9,3.11-3.13,3.17$, and 3.20 follow simply from Bessel's inequality and (1.3).

2. Theorems 3.2, 3.4, and 3.6 are necessary type conditions for absolute convergence and show that most of the results in this paper are best possible.

3. Konyushkov's Theorem 3.14 is also valid for the Walsh and generalized Walsh system, and Theorem 3.10 is a corollary of it.

4. Stechkin's Theorem 3.15 has been enlarged in scope, and its proof simplified.

5. Ciesielski and Musielak's Theorem 3.16 is also valid for the Franklin and generalized Haar system, and Theorems 3.18 and 3.19 are corollaries of it.

\section{REFERENCES}

1. G. Alexits, Konvergenzprobleme der Orthogonalreihen, Akad. Kiadó, Budapest, 1960; English transl., Internat. Series of Monographs Pure Appl. Math., vol. 20, Pergamon Press, New York, 1961. MR 28 \#5292; 36 \#1911.

2. N. Bari, Trigonometric series. I, II, Fizmatgiz, Moscow, 1961; English transl., Macmillan, New York; Pergamon Press, Oxford, 1964. MR 23 \#A3411; 30 \#1347.

3. S. L. Bljumin and B. D. Kotljar, Hilbert-Schmidt operators and the absolute convergence of Fourier series, Izv. Akad. Nauk SSSR Ser. Mat. 34 (1970), 209-217 = Math. USSR Izv. 4 ( 1970), 215-223.

4. S. V. Bočkarev, Absolute convergence of Fourier series over complete orthonormal systems, Uspehi Mat. Nauk 27 (1972), no. 2(164), 53-76. (Russian)

5. — On absolute convergence of Fourier series, Dokl. Akad. Nauk SSSR 202 (1972), 995-997 = Soviet Math. Dokl. 13 (1972), 225-227. MR 45 \#4048.

6. H. E. Chrestenson, A class of generalized Walsh functions, Pacific J. Math. 5 (1955), 17-31. MR 16,920.

7. Z. Ciesielski, Properties of the orthonormal Franklin system, Studia Math. 23 (1963), 141-157. MR 28 \#419.

8. Properties of the orthonormal Franklin system. II, Studia Math. 27 (1966), 289-323. MR $34 \# 3202$. 
9. Z. Ciesiel ski and J. Musielak, On absolute convergence of Haar series, Colloq. Math. 7 (1959), 61-65. MR $22 \# 863$.

10. N. J. Fine, On the Walsh functions, Trans. Amer. Math. Soc. 65 (1949), 372-414. MR 11, 352.

11. B. I. Golubov, Fourier series of continuous functions with respect to a Haar system, Izv. Akad. Nauk SSSR Ser. Mat. 28 (1964), 1271-1296. (Russian) MR 30 \#2283.

12. - On functions of bounded p-variation, Izv. Akad. Nauk SSSR Ser. Mat. 32 (1968), 837-858 = Math. USSR Izv. 2 (1968), 799-819. MR 38 \#3392.

13. —_, A certain class of complete orthogonal systems, Sibirsk. Mat. Ž. 9 (1968), 297-314 = Siberian Math. J. 9 (1968), 225-239. MR $37 \# 680$.

14. B. I. Golubov and A. I. Rubinštein, A class of convergence systems, Mat. Sb. 71 (113) (1966), 96-115. (Russian) MR 34 \#553.

15. I. I. Hirschman, $O_{n}$ multiplier transformations, Duke Math. J. 26 (1959), 221-242. MR $21 \# 3721$.

16. M. Izumi and S. Izumi, $O_{n}$ absolute convergence of Fourier series, Ark. Mat. 7 (1967), 177-184. MR 36 \#4247.

17. A. A. Konyushkov, Best approximation by trigonometric polynomials and Fourier coefficients, Mat. Sb. 44 (86) (1958), 53-84. (Russian) MR 20 \#2571.

18. J. R. McLaughlin, Haar series, Trans. Amer. Math. Soc. 137 (1969), 153-176. MR $38 \# 4900$.

19. - Integrated orthonormal series, Pacific J. Math. 42 (1972), 469-475.

20. C. W. Onneweer, Absolute convergence of Fourier series on certain groups, Duke Math. J. 39 (1972), 599-609.

21. R. E. A. C. Paley, A remarkable series of orthogonal functions, Proc. London Math. Soc. 34 (1932), 241-279.

22. J. J. Price, Certain groups of orthonormal step functions, Canad. J. Math. 9 (1957), 413-425. MR 19, 411.

23. S. B. Stečkin, Absolute convergence of orthogonal series, Uspehi Mat. Nauk 2 (46) (1947), no. 3 (19), 177-178. (Russian)

24. - On absolute convergence of orthogonal series. I, Mat. Sb. 29 (71) (1951), 225-232; English transl., Amer. Math. Soc. Transl. (1) 3 (1962), 271-280. MR 13, 229.

25. O. Szász, Quasi-monotone series, Amer. J. Math. 70 (1948), 203-206. MR 9, 278.

26. T. S. Tevzadze, Absolute convergence of Fourier series, Sakharth. SSR Mecn. Akad. Moambe 57 (1970), 525-528. MR 42 \#49 42.

27. P. L. Ul' janov, $O_{n}$ Haar series, Mat. Sb. 63 (105) (1964), 356-391. (Russian) MR $28 \# 4295$.

28. N. Ja. Vilenkin, On a class of complete orthonormal systems, Izv. Akad. Nauk SSSR Ser. Mat. 11 (1947), 363-400; English transl., Amer. Math. Soc. Transl. (2) 28 (1963), 1-35. MR 9, 224; 27 \#4001.

29. - Supplement to "Theory of orthogonal series" (Russian translation of the book by S. Kaczmarz and H. Steinhaus) (translated with a reviewing article by R. S. Gutter and P. L. Ulyanov, edited with a supplement by N. Ya. Vilenkin), Fizmatgiz, Moscow, 1958; English transl., Amer. Math. Soc. Transl. (2) 17 (1961), 219-250. MR 20 \#1148; 23 \#A 1996. 
30. C. Watari, Best approximation by Walsh polynomials, Tôhoku Math. J. (2) 15 (1963), 1-5. MR 26 \#5329.

31. N. Wiener, The quadratic variation of a function and its Fourier coefficients, Studies in Appl. Math. 3 (1924), 72-94.

32. I. Wik, Criteria for absolute convergence of Fourier series of functions of bounded variation, Trans. Amer. Math. Soc. 163 (1972), 1-24. MR 44 \#3068.

33. L. C. Young, An inequality of the Hölder type, connected with Stieltjes integration, Acta Math. 67 (1936), 251-282.

34. A. Zygmund, Trigonometrical series. Vols. I, II, 2nd rev. ed., Cambridge Univ. Press, New York, 1959. MR 21 \#6498.

DEPARTMENT OF MATHEMATICS, PENNSYLVANIA \$TATE UNIVERSITY, UNIVERSITY PARK, PENNSYLVANIA 16802 